\title{
Adult Unfavorable Prognosis Hodgkin Lymphoma
}

National Cancer Institute

\section{Source}

National Cancer Institute. Adult Unfavorable Prognosis Hodg kin Lymphoma. NCI

Thesaurus. Code C114809.

A Hodgkin lymphoma with unfavorable prognosis that occurs during adulthood. 